
operating models and consider their worldwide matrix organizations to be sources of competitive advantage. Some leadership teams inhabit these models as though they are second nature. Others struggle mightily. No company has completely solved the problems of bringing complex operating models to life, but many have made significant progress. Studying these companies can be productive - there are reasons some deliver superior results while others seem to have real problems.

\section{WHY ORGANIZATION IS AS IMPORTANT AS STRATEGY}

Profitable growth comes not from a firm's articulated strategy but rather its actual strategy, which is reflected in how the organization's resources are allocated. Outdated capabilities, structures, and decision-making processes get in the way of implementing good intentions and block attention to new sources of growth. In effect, the backward pull of structure, if left unattended, can inhibit even the best of strategic plans.

CEOs of large multinational companies can build the bridge from strategy to structure to performance through organizational capabilities. Enterprise-wide capabilities are difficult to build, but are also difficult for competitors to copy. Organizational capabilities are cultivated by the intentional arrangement of structure, process, metrics, and talent. Capabilities are a distinct source of competitive advantage that enable both the rapid execution of strategy and the envisioning of new strategic options. Most of the critical capabilities that drive growth - innovation, brand building, shared resources - are formed at the intersections of business units, functions, and geographic markets as shown in Figure 1 below.

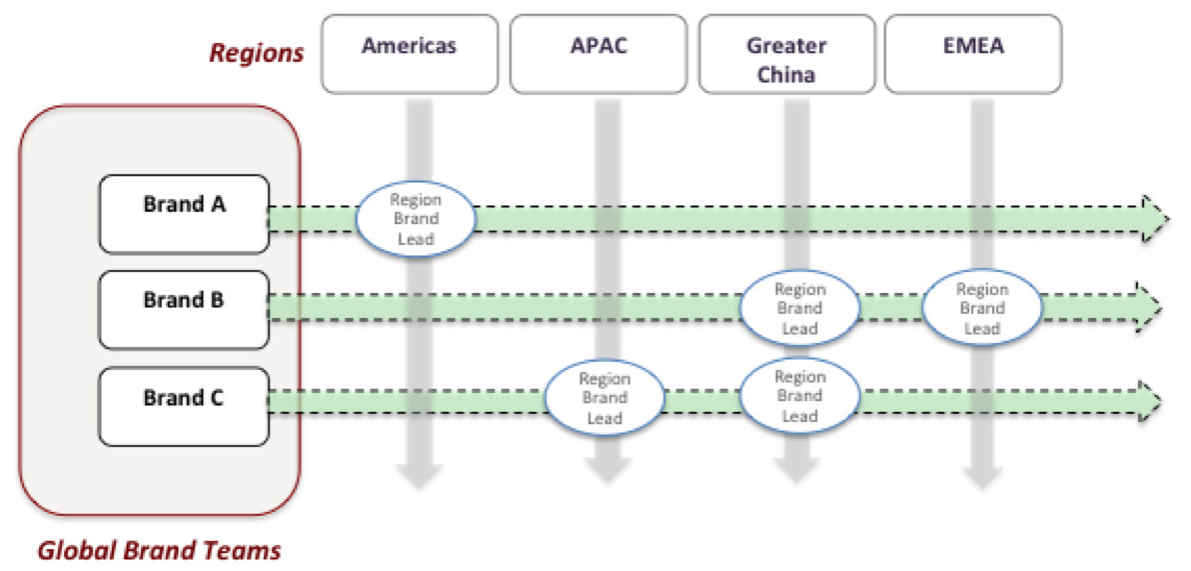

Fig. 1. Growth occurs at the intersections of businesses, functions, and geographies

The global operating model embodies the promise of the matrix organization - that a company can have it all: robust global products and brands, local market responsiveness, and cost-effective functional processes and systems. But, the reality is that many senior executives in companies trying to execute global strategy struggle to meet any of these objectives. It is not because managers do not want to make the matrix work; they have not been set up to achieve enterprise-wide success. Michael Canning, CEO of Duke Corporate Education, notes: "CEOs discuss how their companies have perfected the art of working in silos. But, collaboration across business units remains challenging because people are not properly incentivized, and no single business unit will bear the burden of investing in collaboration" (Canning, 2015).

\section{ACTIVATION}

The pull to greater complexity in global strategy and organization, and all the challenges that come with it, is powered by the need for new sources of growth in diverse geographic markets across multi-product divisions with increasingly demanding customers who have lots of technology at their fingertips (Galbraith, 2014). After working closely with more than 20 large U.S. and European-based global companies (ranging in size from \$3-65 billion) during the past ten years, we have concluded the problem is not in the fundamental design of 
their operating models. The challenge is ineffective and incomplete activation. Despite largescale, well-funded change initiatives, sophisticated communication programs, and countless worldwide leadership summits, the hard work of bringing these complex organization designs to life often lacks focus or is not sustained over the three or more years that it typically takes to fully embed new ways of working.

We are frequently invited into companies a year or two after they have made a substantial organizational change in response to a strategic redirection. We encounter frustration that the new operating model - which is often quite logical and compelling - is not resulting in the predicted business performance. As we look across the companies we have studied and worked with, we see a common set of symptoms that indicate incomplete activation:

- Excess hierarchical layers and duplicated work make the organization slow and internally focused.

- Global product teams and functions are overlaid on the existing regional (commercial) organizations without making adjustments in legacy P\&L structures, creating unproductive friction.

- Power issues remain unresolved across global business units, regional teams, and functional units.

- Global functions are designed to do yesterday's work, often independently from the needs of the business.

- Leaders do not know how and are not motivated to work in a matrix - metrics and reward systems do not reinforce enterprise thinking.

- The corporate executive committee continues to act as a group of individual leaders, each focused on their own business versus the needs of the enterprise.

Activation is different from the design and implementation task. These are both somewhat static and time-bound activities. Activation starts with design, and is dependent on good implementation, but goes beyond the "go-live" date. With activation, there is learning and adjustment that can only come through leaders and managers engaging horizontally across organizational boundaries through a series of business decision-making cycles, and then analyzing and reflecting on outcomes. Finally, activation is achieved when the necessary modifications in structures, processes, metrics, or behaviors are made based on this learning. Consider a simplified example of a fashion apparel company to illustrate the definitions and concepts associated with the activation process.

Strategy and growth choices: A U.S.-based fashion company wants to expand its brand into Asia and move from its core women's clothing and shoe collection to adjacent categories (men's clothing, accessories, fitness, etc.).

Global operating model: The shift is from a single business run out of the home region with two categories to multiple regions and multiple categories supported by global functions.

Organization design: The company establishes U.S., European, and Asian regional leadership, new global category teams, and end-to-end global functional management delivered through region-based staff. "Collection integration" is identified as a key process to enable the new organizational model. The collection integration process will involve local merchants as well as designers from across the categories in each phase of design to ensure alignment on the core brand message, infusion of local innovations and tastes into global decisions, and sharing of patterns and themes across the categories.

Implementation: Regional and category roles are designed and staffed. The collection integration process is laid out in detail including participants, routines, and decision rights.

Activation: Over the next 24 months, the process for creating an integrated collection is run three times per year. Following each session, there is an after-action review, and all aspects of the process and results are assessed. Modifications are made to participation, timelines, and decision processes. Metrics are adjusted to drive and reward the right collaborative behaviors. The collection-integration process becomes a dynamic forum for strategic and operational conversations and decisions to take place at the nodes where unique value can be captured. This is an example of how a well-designed and tended process allows a company to gain the rewards of strategic complexity. 
Depending upon the pace of the business and the opportunities for leaders to engage in various decision cycles, full activation of a global operating model can take several years as activation is an adaptive and dynamic activity.

\section{FIVE KEY ACTIVATORS}

Our consulting work and research reveal five activators for accelerating business results in a global operating model. We believe these activators are what differentiate companies that gain sustainable results from their global operating model from those that do not. The activators are sorted against three outcomes: the right connections, the right conversations, and the right know-how. See Figure 2.

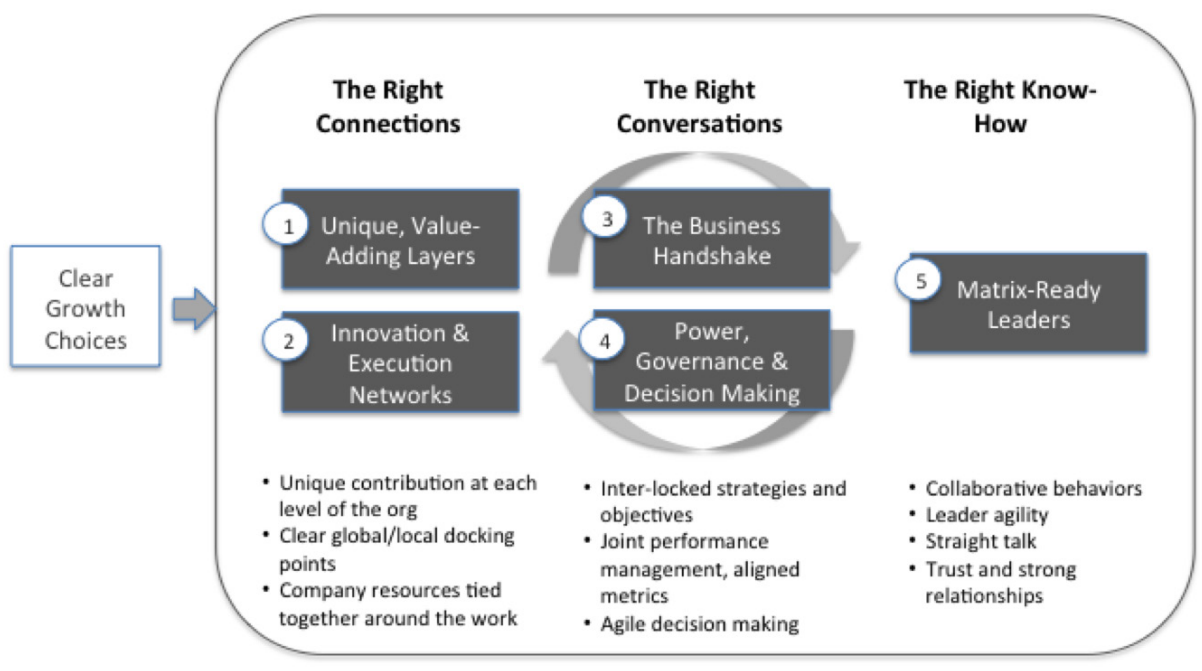

Fig. 2. The five activators of the global operating model

\section{The Right Connections}

Establishing an organizing logic that fits the strategy is fundamental to organization design (Donaldson, 2014). The basic structural options, however, are limited. All global organizations are built around combinations of global products, brands, or customer groups; regional or local geographic market units; and global operating and support functions. The design task is to define the working connections among these groups. Integration is fundamental to the global operating model, and most managers are presented with scores of opportunities to connect with colleagues across the organization. Management time is scarce, so the right connections should be designed to make collaboration as efficient as it can be (Kesler \& Kates, 2011). Two of the five activators help assure that the right connections are wired into the organization.

Activator \#1: value-adding hierarchical layers. Make sure that hierarchical layers do not overlap in responsibility and create unnecessary complexity. Two years into the rollout of its global operating model, Heineken, the worldwide brewing company, discovered confusion in the working roles of global brand teams and commercial regions, due largely to overlapping responsibilities between the region and country-level management (see Figure 3). This problem is common in global organizations. It is important to establish one operating-unit layer of organization and a single value-added layer for consolidating functional work. This ensures that:

- The fewest possible layers are established, each with a unique value-adding contribution, which facilitates delegation, empowerment, and faster vertical decisionmaking.

- An anchor layer is established to be the primary owner of profit and loss, and this layer becomes the key focus for partnerships between global and regional units, being careful that this work is not duplicated in other layers of the organization. 
- Infrastructure and support activities are consolidated where possible and not replicated at multiple levels, reducing complexity and cost.

Global Beer Brands

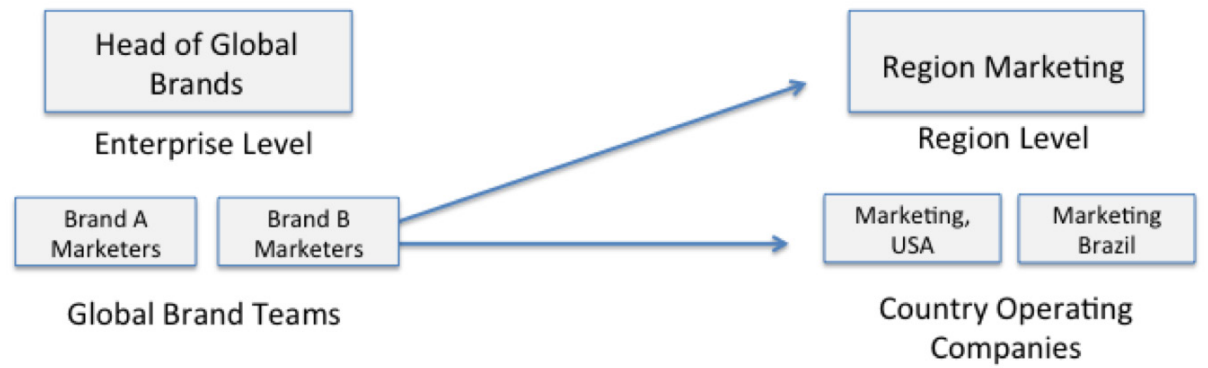

Fig. 3. Heineken's global brand teams had to interact with multiple layers of commercial and P\&L units at both the region and country levels in the company's older operating model.

The Coca-Cola Company provides another example of the need to adhere to the principle of unique, value-adding layers. In late 2014, senior leaders announced a company-wide initiative to establish an anchor layer of management in its international markets. Large clusters of countries, known as divisions, became the anchor operating-unit layer. The company eliminated its regional-group layer in order to create a direct connection between field divisions and global brand and category teams. The changes were designed to "rewire our organization for faster and more effective decision-making," said CEO Muhtar Kent in an internal memorandum to employees (Esterl, 2014). The Coca-Cola system had become a complex web where big ideas, driven from the center, had to be negotiated with each region, and often country-level general managers, before they could be executed. By having the center-based marketers interact directly with countries or small clusters of countries, brand building and product expansion ideas can be driven more quickly around the world.

The anchor layer is where authority is located to make short- and long-term trade-offs. By removing the regional layer, Coca-Cola placed the anchor layer close to the consumer. Now the center marketers provide global direction, but only after interaction with local marketers who are in close contact with consumer trends. In this business, a regional marketing view did not add value.

Activator \#2: innovation and execution networks. Build formal networks of global and local capability with guidance from the center. This ensures that:

- Ideas move not just from the center to the operating units but also across business units and geographies to generate innovation.

- The enterprise can provide strong, coordinated leadership from the center without relying on reporting relationships, for greater agility in the regions.

- Investments in people and systems are leveraged for the good of the entire company.

- Execution for initiatives is owned by the network, creating better accountability for results.

Keith Weed, the chief marketing officer at Unilever, and his colleagues at EffectiveBrands, have argued that marketing, as a capability, has now become too important to be managed solely by the marketing function (Arons, van den Driest, \& Weed, 2014). Today's marketing capability can only be fully realized by engaging the entire organization in pursuing the brand's purpose, integrating marketing with other functions, and ensuring that global, regional, and local marketing teams work interdependently. The same idea can be extended to the management of initiatives like innovation or key account management. To leverage innovation investments - to make them "go-forward compatible" and be relevant to customers in more than one region - businesses such as Nike, Medtronic, and Deere \& Co. engage product developers from several regions to work with each other, often facilitated by a corporate team, against a shared agenda and targets. Common goals, methods, and tools are the integrator, the centripetal force that allows the work to be center-led not centralized. 
The center has an important role in the network, but it is not the dominant role. Leadership is often rotated in robust, global networks. For example, PepsiCo connects global category managers with regional commercial and marketing managers from developed and developing markets. Any operating unit in the network might be designated as the lead for creating the content for a given innovation initiative. An operating unit or function in the network often assumes the lead when it has a major stake in the outcome, has the talent to lead the work, and is willing to invest resources. Some businesses or regions within the network may commit to launch the new product or brand idea early in the process and share in the funding. Other units may serve as a test market for the new idea. While some operating units in the network may completely opt out of a given initiative, other units may pick up the content once it is developed and adapt it locally. These "coalitions of the willing" are built on trust and a culture of mutual interdependence. There is no chief marketing officer at PepsiCo.

\section{The Right Conversations}

The purpose of organization design is to shape "strategic conversations" (Liedtka, 2010). The metaphor of organization as conversation recognizes the organization as a set of dynamic patterns of thought and behavior that cannot be separated from the realities of human interaction. This is in contrast to the common metaphor of organization as machine, a set of blueprints that aim for control (Suchman, 2011). Trying to perfect the organization as a machine only creates stress, blame, and defensiveness when events inevitably stray from the plan. For example, the response to the uncertainty of global complexity must be mindful participation in real-time problem-solving, not the rote following of prescribed decision rights. The "right" conversations require managers that have the right skills, mindsets, and behaviors, but these exchanges can be fostered through design of smart operating mechanisms. There are two critical activators that lead to the right conversations.

Activator \#3: the business handshake. In one sense, an organization is made up of a series of requests and promises between people (Sull \& Spinosa, 2007). The most important of these are what we call the "business handshake", which can be characterized as follows:

- It is the agreement across organizational boundaries on what results will be delivered and how.

- Goals are shared completely. The partners co-own the business customer and/or the consumer, they co-develop strategy, and they co-own the results.

- An integrated planning process connects strategic plans, including operating targets and budgets, and - in the handshake - it connects the partners across business lines, geographies, and functions.

Once interlocking targets and resource plans are set, the principals in the handshake own the execution of those plans. They will need to (a) align rewards and metrics, (b) develop a performance-management cadence that pulls the players together to manage results at the right level of detail and with the right frequency, and (c) create access to the same data for all partners, ensuring a single source of information and knowledge to empower smart tradeoffs.

At Royal Philips, global-local target setting conversations are structured around the organizational nodes in the matrix that deliver the most value against the strategy. With its 20 global product businesses (the business-unit anchor layer) and its 17 key market clusters (the market anchor layer), a planning grid can be laid out for what CEO Frans van Houten refers to as the more than 300 possible "business-market combinations." The Pareto principle is applied to focus on those 20 percent of the cells in the grid that will deliver something close to 80 percent of the growth target for the company. For example, the oral health market in Brazil, where people brush their teeth three times a day, is an outstanding business-market combination for Sonicare toothbrushes. To exploit this opportunity requires targeted and collaborative investment in innovation, brand building, and commercial excellence. The worldwide head of Sonicare and the commercial head of Brazil co-own the plan for growth, similar to the illustration in Figure 4. 


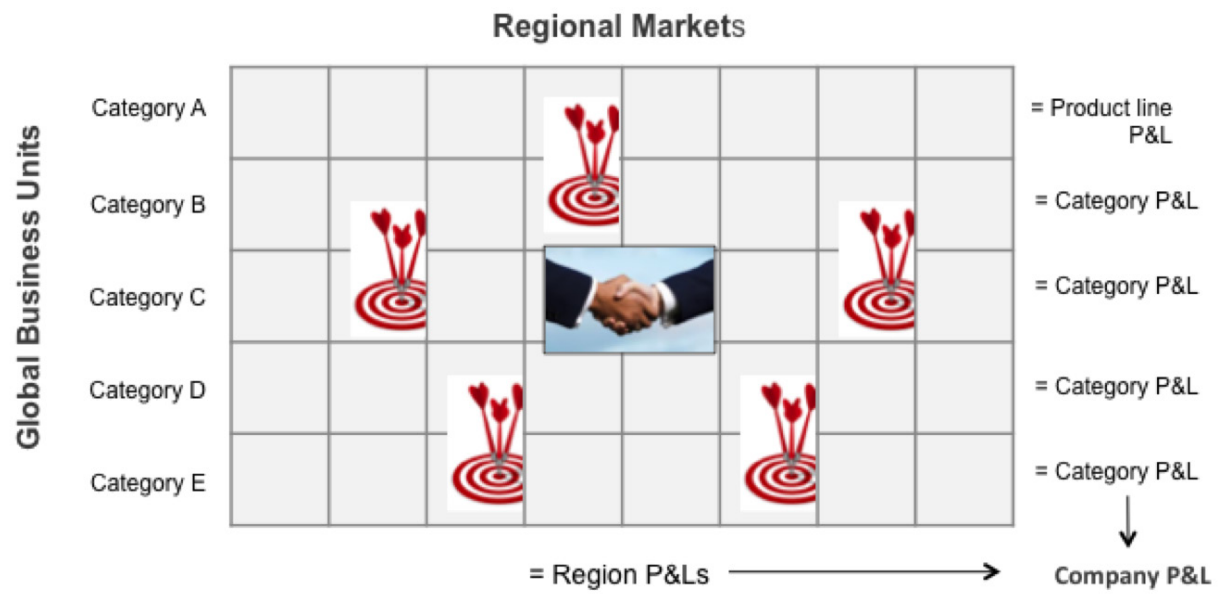

Fig. 4. Business-market planning grid

Activator \#4: power, governance, and decision-making. Decision-making is the essence of management, and one key to activating the global operating model is to allocate power for purpose. Once the handshake is set with interlocked plans and a shared business dashboard, operating governance forums and practices enable both agility and scale. This is rarely accomplished with RACI charts (responsible, accountable, consulted, informed). Decision-making takes place in a culture. In a global operating model, organizational culture must support the right balance of global, local, and functional influence, and it must value empowerment of cross-boundary teams. Decision-making in companies that have fully activated their operating models has the following characteristics:

- Company forums for decision-making (executive committees, operating committees, policy councils, and the like) provide clear strategic direction and guidance to operating leaders.

- Simple, co-owned decision rights are focused on the highest-value decisions in the handshake, and they line up closely with accountabilities.

- Partners in the handshake work together with a regular cadence, transparency, and action focus.

- The power to decide and act is delegated to the accountable managers, and top executives intervene only on an exceptional basis.

Before using decision-making tools such as RACI charts, it is important to define clearly what the governance forums in the enterprise will be, and what role each will play. Examples of governance forums include executive committees, operating committees, and councils focused on specific topics such as growth strategy, innovation project portfolio, pricing, marketing policy, or IT standards. Most companies have a variety of these forums in place, but often their remit is unclear, they may overlap in some decision areas, and they may leave gaps in others. Corporate executive committees can empower anchor business units by creating strategic clarity for business decisions, such as stating the new-product investment priorities. This center-led, integrative executive work creates the framework in which managers close to the ground can be free to act. It provides them the context in which to make good decisions and judgments. It reduces the need for approval levels and controls around each transaction. Clear direction on priorities and boundaries from the top is required for true empowerment in the middle.

The starting point for setting decision rights among the horizontal partners is to recognize the benefit of tension that is built into the matrix. Tension in the matrix draws energy to sources of value that may compete in the short run (e.g., regions driving revenue growth vs. business units driving operating margins) but which are important to the long-term health of the company. The goal of effective decision rights is to let that tension play out until the best decision for the business can be made. Effective decision rights allow for true empowerment and speed by enabling managers to make sound choices at the lowest practical level possible. When the company has adopted a planning and control process built around a business- 
market handshake, there is a context for decision rights, and they can provide real guidance for leaders.

\section{The Right Know-How}

The characteristics of the global, boundary-spanning leader have been examined in-depth over the past decade or more (Ernst \& Chrobot-Mason, 2010). In companies that fully activate their global operating model, a pipeline of matrix-ready leadership is the sum of embedded selection and development practices, clearly defined behavioral criteria, and deep commitment to talent development at the top of the hierarchy.

Activator \#5: matrix-ready leaders. Leaders who succeed in the global matrix are selected and developed for their learning agility, influence skills, and ability to engage in the tensions among naturally competing priorities (Osland \& Bird, 2012). No amount of formal process, aligned objectives, or decision-rights documents will bring the global operating model to life without the right leadership behaviors and relationships. In companies that make their operating model work:

- Global leaders are able to manage conflicts between global and local business (and functional) objectives across the matrix.

- $\quad$ Relationships and social capital - which are the foundation for effective leadership in all organizations - are strengthened and valued.

- Collaboration and working across all types of boundaries become the cultural norm for leaders.

The matrix that underlies a global operating model requires strong leaders that can manage multiple teams, influence peers without authority, and proactively align competing agendas. The success of a global operating model depends largely on competent leaders who are willing and able to navigate the power dynamics inherent in a complex organization. Building a global talent pipeline is a core capability for companies that want to activate a global operating model. Clear talent objectives drive the right talent-development focus. Procter \& Gamble provides a good example. Senior-level talent is needed in three broad areas: (a) global business units, (b) market development regions, and (c) functions and services. Talent depth is measured in each area, and strategies are built to close projected gaps.

The best global leadership systems develop people and the organization simultaneously (Tichy et al., 1992). No other business process has more impact on shaping culture than company-wide talent-development forums. Calibration and development councils can become the control center for activating the global operating model if used well. As an executive team at the top does the work of getting to know its talent by evaluating individuals with a common yardstick and vocabulary, they begin to calibrate a shared set of expectations about what global leadership looks like in their company. As senior executives plan moves among promotable candidates, they learn to trust, and they play more of an enterprise leadership role, often becoming a more collaborative leadership team. For many companies, these talent review discussions help to shift the role of each senior executive from being focused on the performance of his or her own unit to committing a portion of his or her attention to shared leadership of the enterprise. By investing in the talent conversation, they are "being the change", working together to activate the global operating model.

In our work with global companies, we have found that learning programs can also play a major role in developing leaders, especially in the midst of a transition to a new operating model. Such sessions help people understand the new organizational intentions and reassure them that the challenges they are experiencing are normal and expected. When education and awareness are combined with skill building and the opportunity to successfully co-create with new colleagues, managers are more open to taking personal risks to change behavior. Three kinds of learning, when woven together, have the simultaneous effect of developing the organization and its leaders: (a) understanding the fundamentals of matrix logic; (b) building trusting relationships and networks, and (c) co-creating robust management processes and operating mechanisms. Such learning is best delivered as case-based, action-learning workshops that diagnose the health of the organization while enabling leaders to succeed in the matrix. In this way, the workshops support activation by serving as a feedback loop 
of input and insight to executives regarding what course corrections need to be made to the change management plan.

\section{CONCLUSION}

The power of the five activators is in their interdependence and mutual reinforcement. For example, no matter how motivated and skilled a set of managers is, if the organization has not provided the forums and processes to connect and have the right conversations, a lot of well-intentioned individual effort will be wasted. Conversely, no amount of reengineering of business processes will make up for a management team that is unwilling or unable to engage in collaborative behavior. The activators also work together at a more subtle level. For example, identification of the anchor layer sets up who needs to come together in the business unit/region handshake. Well-designed target setting and performance review meetings build trust and social capital over time. Functions that are designed explicitly as an integrative mechanism help to move talent around the world, creating a pipeline of ready leaders able to engage in innovation and execution networks.

The right organization design is a critical part of successful strategy execution. Design, however, is not enough. Activation of the global operating model is the bridge to performance. Activation is the deliberate and adaptive creation of new work, decisions, and business outcomes gained through the repetition and refinement of management processes and interactions over time, enabled by well-designed organizational arrangements and collaborative mindsets. In large multinational companies, full activation may take three years or more. During that time, leadership needs to continue to build horizontal capabilities made up of effective processes, governance mechanisms, collaborative networks, and the right leadership skills and behaviors. The five activators framework provides a road map for assessing current realities and setting concrete plans for the activation of complex, global operating models.

Acknowledgements: We want to thank Dorthe Døjbak Håkonsson for recommending that we introduce the activator concept to the organization design literature. We describe the full activation process in Gregory Kesler and Amy Kates, The Bridge from Design to Performance: Five Ways to Activate a Global Operating Model (Wiley, 2015).

\section{REFERENCES}

Arons MdeS, van den Driest F, Weed K. 2014. The ultimate marketing machine. Harvard Business Review (July-August).

Canning M. 2015. From collaboration to choreography. Dialogue (March 4), Duke Corporate Education, Duke University, Durham, NC.

Donaldson L. 2014. Fit - the key to organizational design. Journal of Organization Design 3(3): 38-45.

Ernst C, Chrobot-Mason D. 2011. Boundary Spanning Leadership: Six Practices for Solving Problems, Driving Innovation, and Transforming Organizations. McGraw-Hill, New York, NY.

Esterl M. 2014. At Coke, newest flavor is austerity. Wall Street Journal (December 23). http:// www.wsj.com/articles/at-coke-newest-flavor-is-austerity-1419352337.

Galbraith JR. 2014. Designing Organizations: Strategy, Structure, and Process at the Business Unit and Enterprise Levels. Jossey-Bass, San Francisco, CA.

Kesler G, Kates A. 2011. Leading Organization Design: How to Make Organization Design Decisions to Drive the Results You Want. Wiley, New York, NY.

Liedtka J. 2010. Strategic conversations at Suncorp Commercial Insurance. Darden Business Publishing, University of Virginia, Charlottesville, VA.

Osland JS, Bird A. 2012. Process models of global leadership development. In M.E. Mendenhall et al., Global Leadership: Research, Practice, and Development. 2nd edition: 97-112. Routledge, New York and London.

Suchman AL. 2011. Organizations as machines, organizations as conversations: Two core metaphors and their consequences. Medical Care 49: 43-48. 
Sull DN, Spinosa C. 2007. Promise-based management: The essence of execution. Harvard Business Review (April): 1-10.

Tichy NM, Brimm MI, Charan R, Takeuchi H., 1992. Leadership development as a lever for global transformation. In V. Pucik, N.M. Tichy, and C.K. Barnett (eds.), Globalizing Management: Creating and Leading the Competitive Organization: 47-60. Wiley, New York, NY.

\author{
AMY KATES \\ Owner \\ Kates Kesler Organization Consulting \\ E-mail: amy@kateskesler.com
}

\title{
GREGORY KESLER
}

Owner

Kates Kesler Organization Consulting

E-mail: greg@kateskesler.com 